Bull. Fac. Agric.,Cairo Univ., 63: 217-225 (2012).

\title{
THE EFFECT OF INTERACTION BETWEEN Azotobacter chroococcum BACTERIA INOCULATION, NITROGEN FERTILIZER AND SULFUR ON GROWTH AND YIELD OF TOMATO
}

(Received: 11.3. 2012)

\author{
By \\ F.M. Suhal, A.A. Al-Rawi* and A.H.Fahmi \\ College of Agricultural University of Diyala and * College of Agricultural University of Anbar,Iraq
}

\begin{abstract}
A greenhouse experiment was condunted in sandy loam soil at the College of Agriculture ,University of Diyala, to investigate the effect of interaction between $A$. chroococcum bacteria and five different levels of nitrogen $\left(0,40,80,120\right.$ and 160) $\mathrm{kgN} \mathrm{ha}^{-1}$ and three levels of sulfur $(0,100$ and 150$) \mathrm{kgS}^{\mathrm{ha}} \mathrm{h}^{-1}$ on growth and yield of tomato. A factorial experiment with a complete randomized block design (CRBD) was carried out.

Significant differences were found between inoculation factor, nitrogen and sulfur levels and their interaction for all the studied traits. Bacterial inoculation caused significant increase in plant length (16.44\%), dry weight (25.75\%), number of phalanges (13.24\%), number of branches (13.42) and the tomato yield ( $5.89 \%$ ) compared without addition inoculation, and regardless the application of nitrogen and sulfur fertilizer. The treatment $\mathrm{N}_{120}$ with bacterial inoculation was superior to other nitrogen treatments. The treatment $S_{150}$ with inoculation was superior to other sulfur treatments with and without addition of inoculation in all the traits.

The treatment $\mathrm{N}_{120}+\mathrm{S}_{150}$ with inoculation gave the highest plant height $(157.5 \mathrm{~cm})$, dry weight $(235.0)$ gm .plant ${ }^{-1}$, number of phalanges ( 40.5), number of baranches (14.0). The highest yield ( 60.5 ) ton.ha ${ }^{-1}$ was produced from the treatment $\mathrm{N}_{160}+\mathrm{S}_{150}$ without inoculation and no significant differences were found between the two treatments $\mathrm{N}_{120}+\mathrm{S}_{150}$ ( 60.01)ton.ha ${ }^{-1}$ and $\mathrm{N}_{80}+\mathrm{S}_{150}$ (59.0) ton.ha ${ }^{-1}$ with inoculation . It can be concluded that the treatment $\left(\mathrm{N}_{80}+\mathrm{S}_{150}\right)$ was more economical and best one.
\end{abstract}

Key words: Azotobacter chroococcum, nitrogen fertilizer, sulfur, tomato

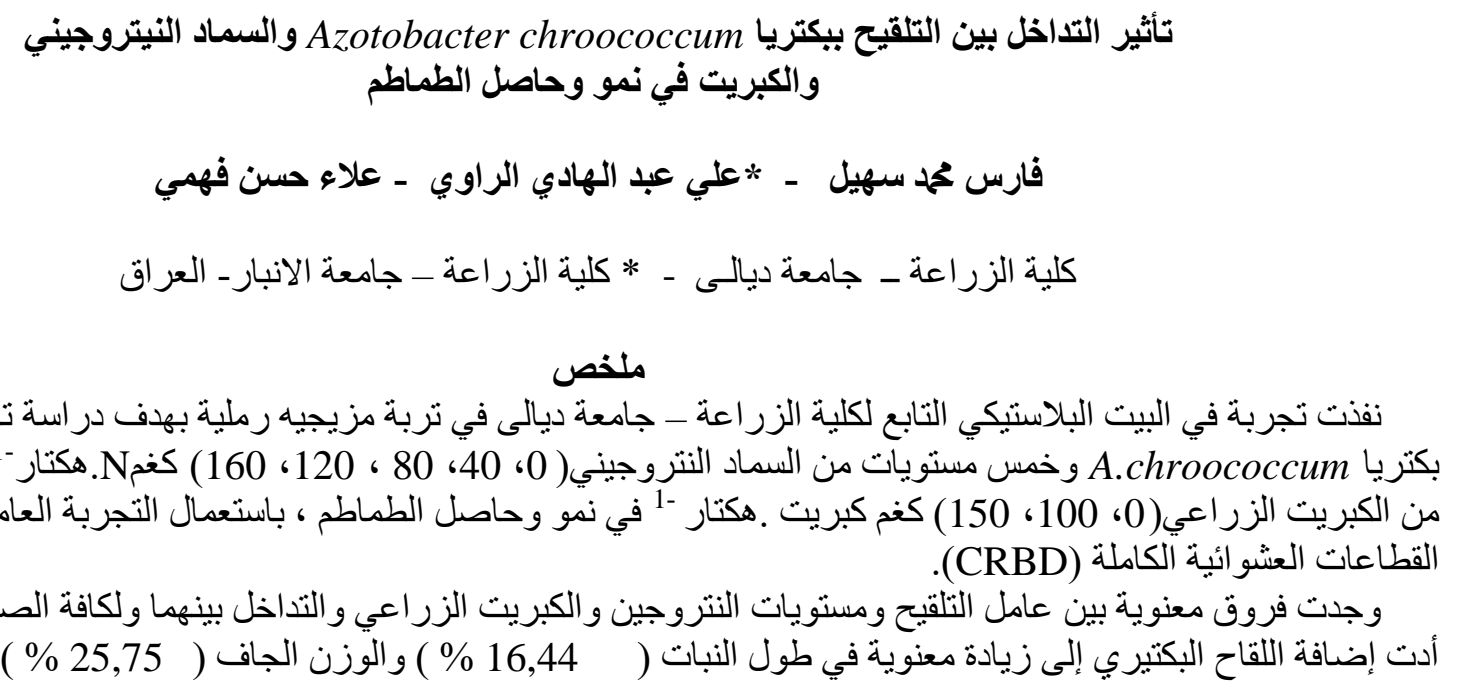


(13,24\%) و عدد الأفرع (13,42 \% \% ) و الحاصل الكلي للطماطم (5,89 \% ) مقارنة بعدم إضافته بغض النظر عن إضافة السماد

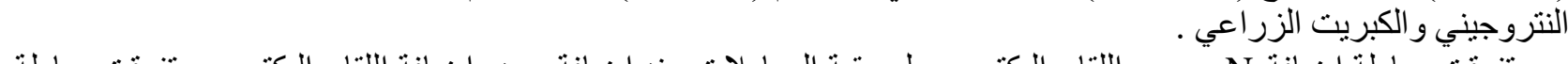

تفوقت معاملة إضافة

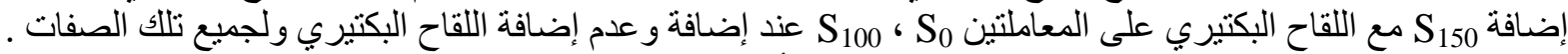
سجلت معاملة إضافة

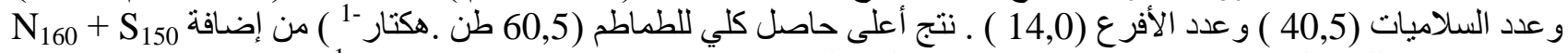
وبدون إضافة اللقاح البكتيري وبفروق غير معنوية عن المعاملتين طن. هكتار -1 وبإضافة اللقاح البكتيري ـ تعد المعاملة الأخيرة هي المفضلة وان البكتريا وفئ وفرت 50 \% من كمية السماد النتروجيني .

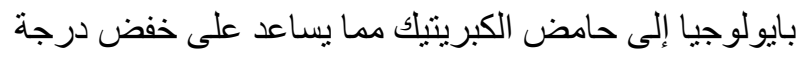

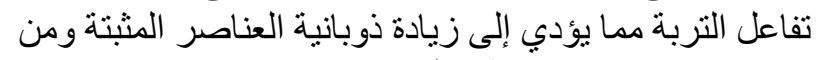

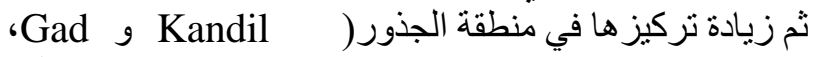

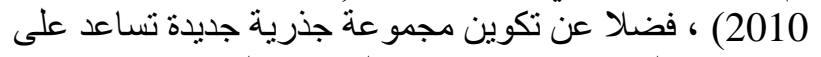
رفع كفاءة النباتات في امتصاص العناصن العناصر الغذائية Landemann)

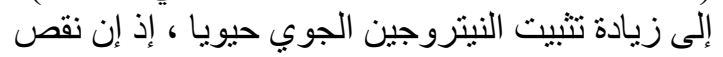

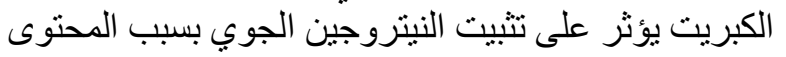

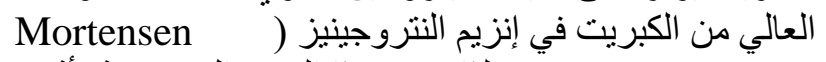

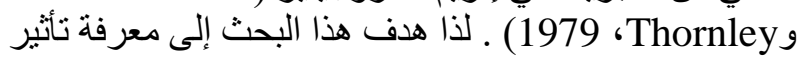

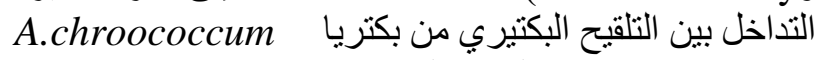

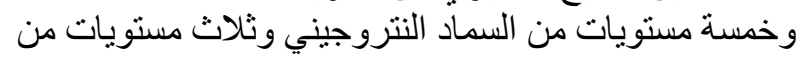

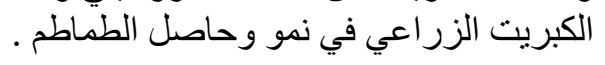

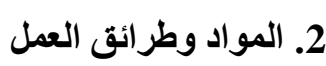

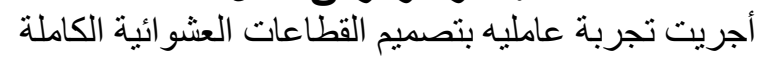

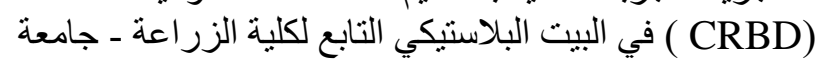

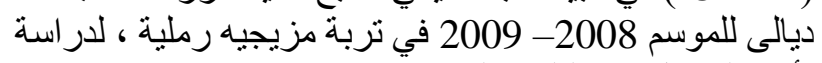
A. chroococcum تأثير التداخل بين التلقيح البكتيري و السماد النتروجيني و الكبريت الزيكين الزر اعي في نمو وحاصل

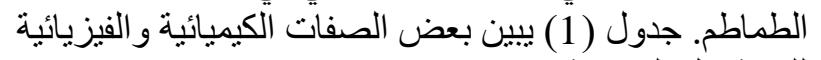
للتربة قبل الزر اعة.

تضمنت التجربة ( اعة 30) معاملة نتجت من التداخل بين

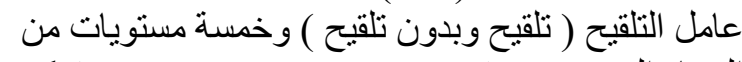

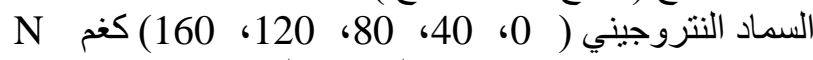

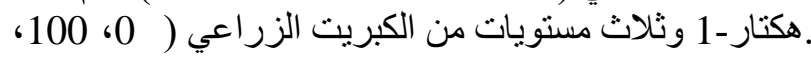

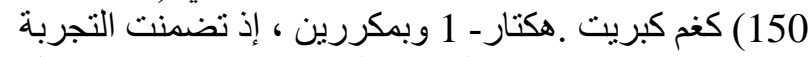

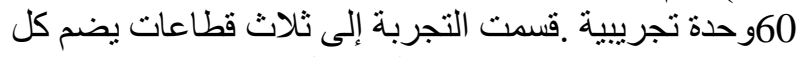

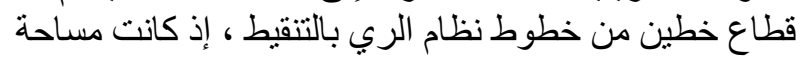

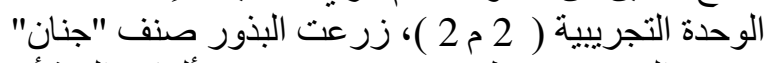

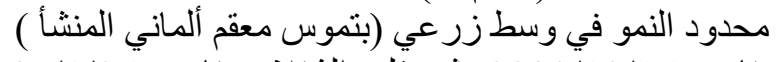

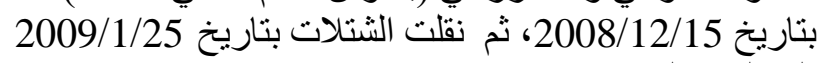

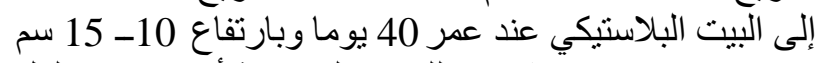

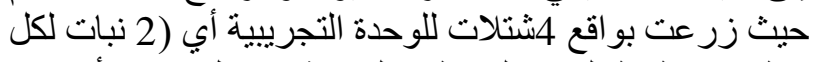

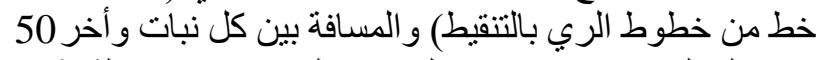

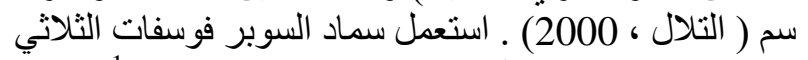

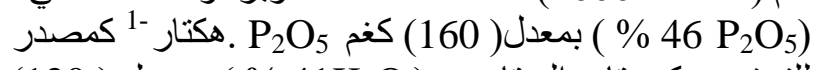

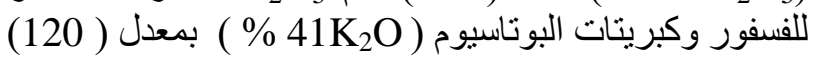

\section{1. المقدمة}

تتميز الأسمدة الكيميائية المستعملة عادة بزيادة إنتاجية

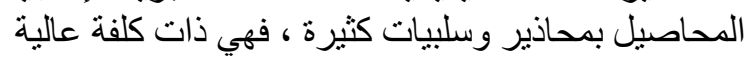

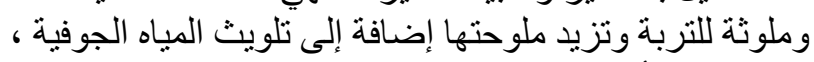

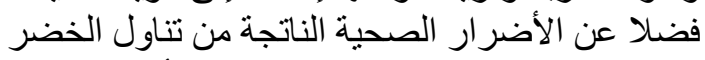

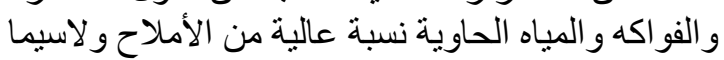

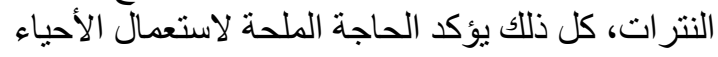

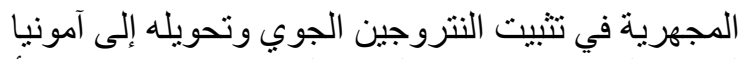

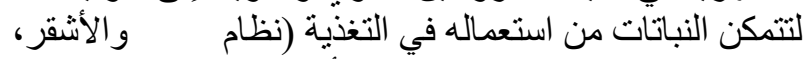

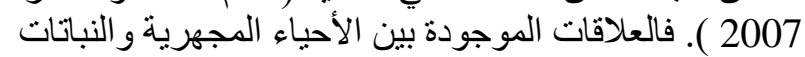

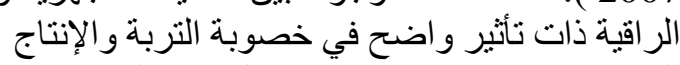

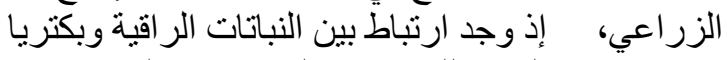

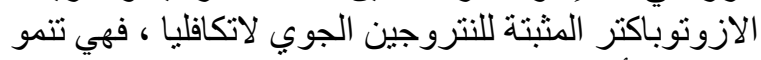

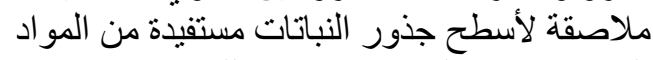

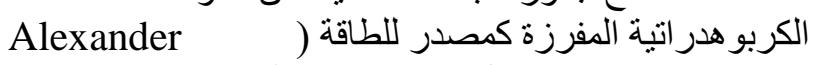

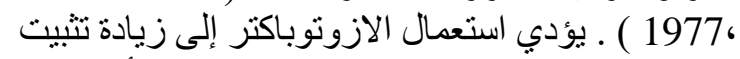

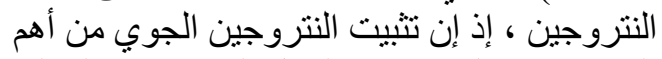

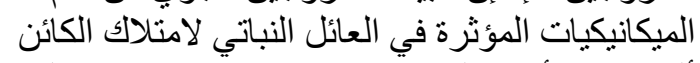

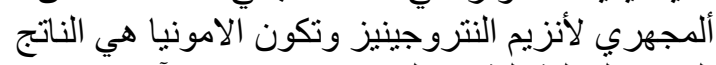

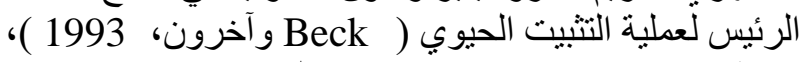

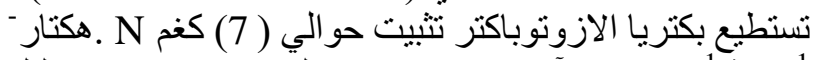

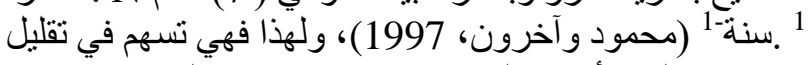

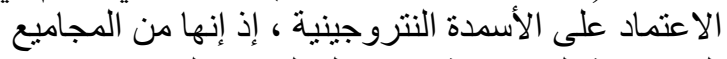

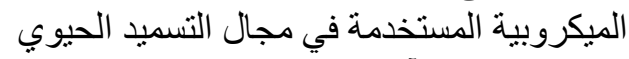

(Mashhoor)

تتصف الترب العر اقية بقلة محتو اها من المادة العضوية

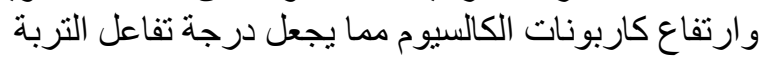

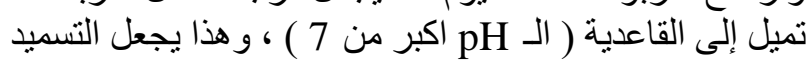

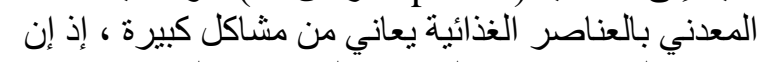

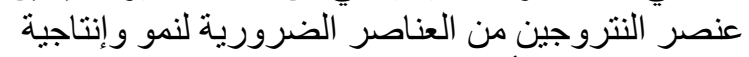

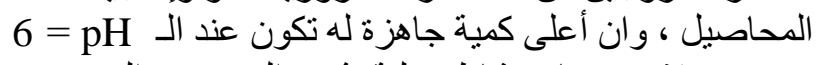

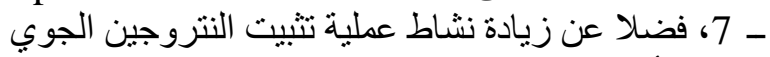

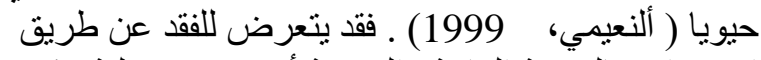

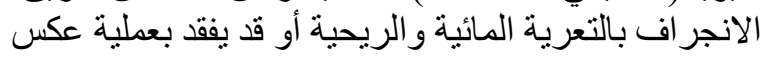

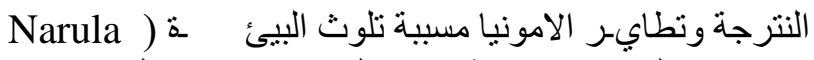

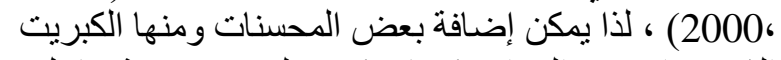

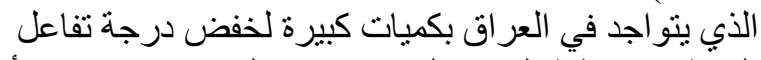
التربة في منطقة الجذور للاستفادة من المغذيات ، إن إذ انه يتأكسد 
النتروجيني و الكبريت الزر اعي تأثثير ا معنويا في أطو ال

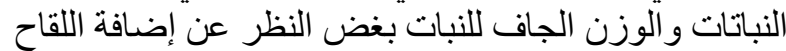

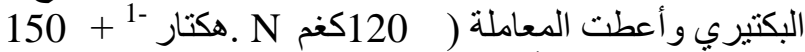

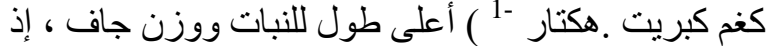

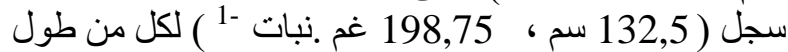

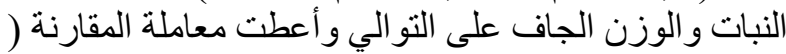

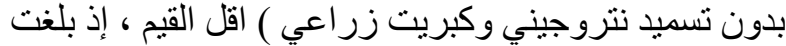

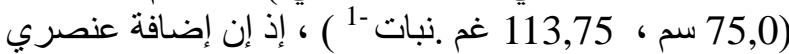

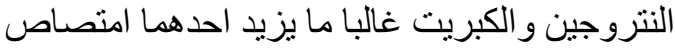

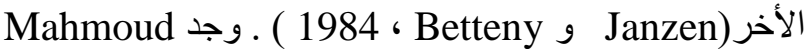

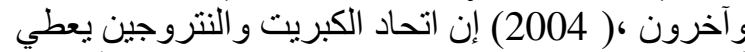

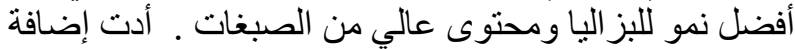
اللقاح البكتيري من بكتريا

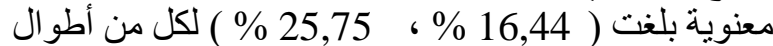

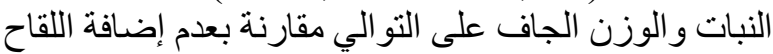

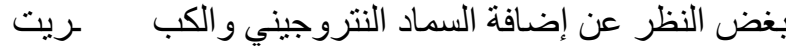

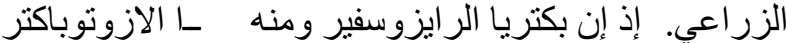
تحسن نمو النبات بو اسطة خفض مستو يات الزئن الاثلين في الجذور

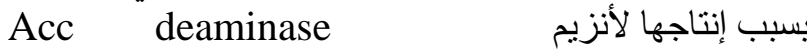
و و إذابة (aminocyclopropane -1- carboxylate

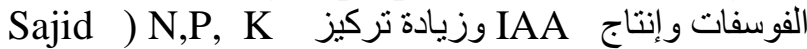

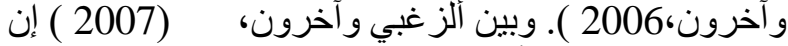

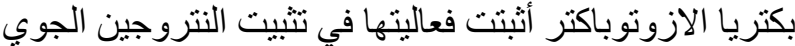

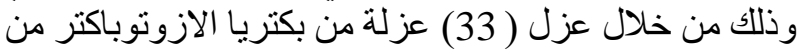
بعض الترب السورية ـ أوضح Govedarica و وآخرون (1993) استعمال صنفين من الطماطم فان بكتريا A.chroococcum أدت إلى زيادة طول النبات و الوزن الجاف ومحتوى النتروجين من خلال قابلية البكتريا على إنتاج منظمات النمو و الاندول و الفينول و الجبرلين خلين.

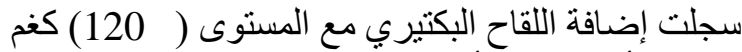

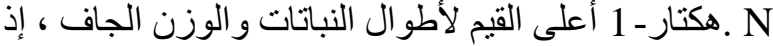

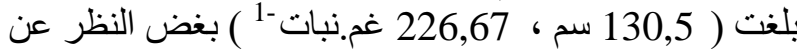

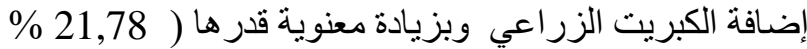

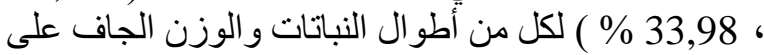

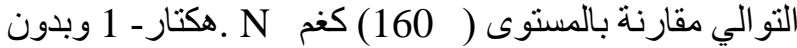
إضافة اللقاح البكتيري ، إذ بلغت ( 107,16 سم ، 169,17

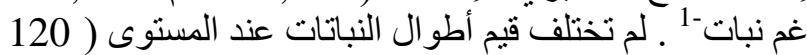

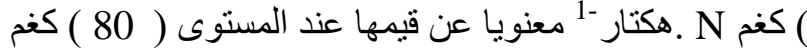

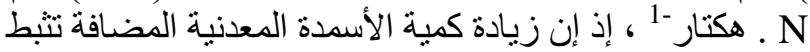

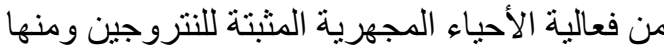
الازوتوباكتر (Govedarica وآخرون، 1995). أشنار سهيل وآخرون، ( 2010 ) إن إضنافة

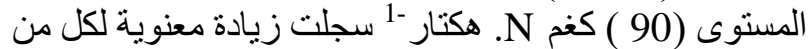

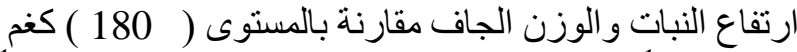

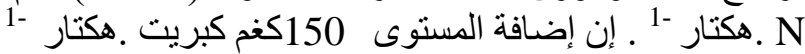

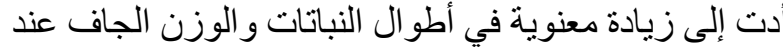

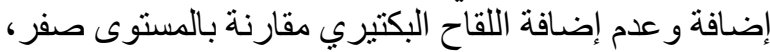

كغم K2 هكتار -1 مصدر ا للبو تاسيوم ، أضيفت هذه الأسمدة

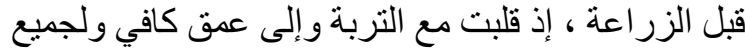

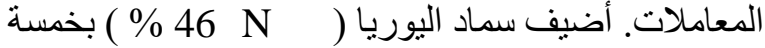

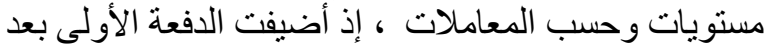

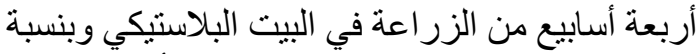

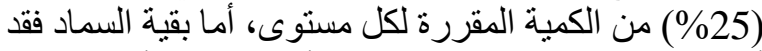

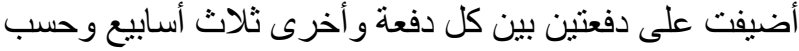

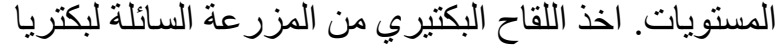

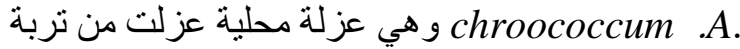

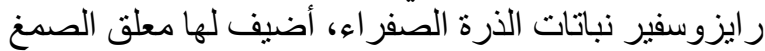

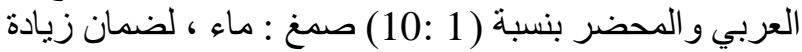

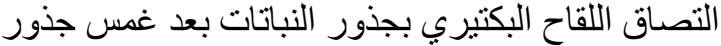

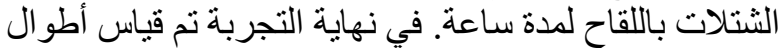

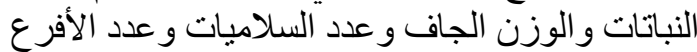
و الحاصل الكلي للطماطح.

\begin{tabular}{|c|c|c|}
\hline 4.6 & |ديسيسمنز.م-1 & EC التوصيل الكهربائي \\
\hline 7.4 & & درجة التفاعل \\
\hline 8.45 & غم. كفم 1- & المادة العضوية \\
\hline 25.82 & \multirow{3}{*}{ ملفم .كفم-1 - مل } & النتروجين الجاهز \\
\hline 29.80 & & الفسفور الجاهز \\
\hline 127.33 & & البوتاسيوم الجاهز \\
\hline مزيجيه رملية & & النسجة \\
\hline
\end{tabular}

\section{3. النتائج والمناقشة}

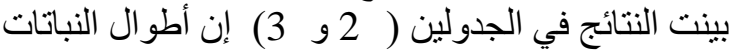

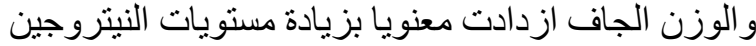

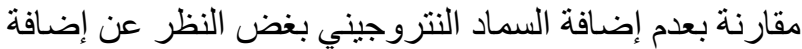

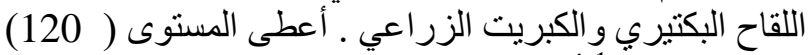

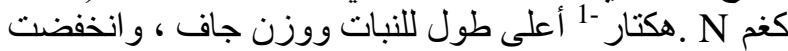

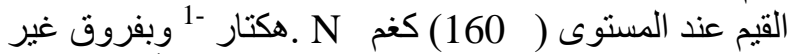

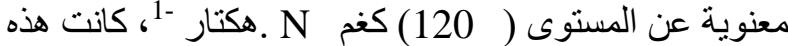

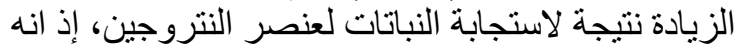

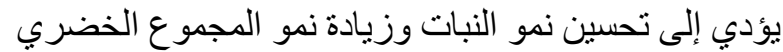
(Tisdale)

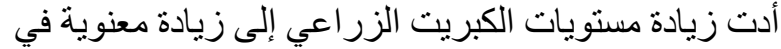

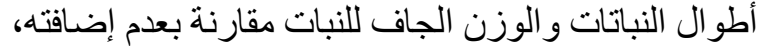

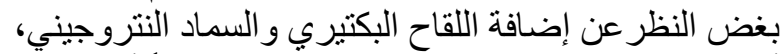

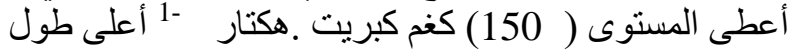
للنبات ووزن جاف ـ إن إضافة الكبريت إلى التربري التربت الكلسية

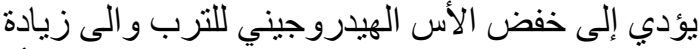
الجاهزية الغذائية في التربة ولاسية الايما الفسفور نتيجة لأكسدة

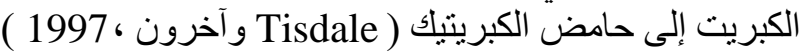

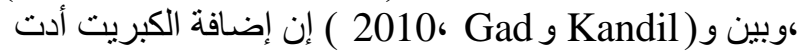

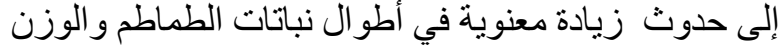
الجاف للمجموع الخضري ـ كان للتداخل بين مستويات السماد التران 
جدول (2): تأثير التلقيح البكتيري ومستويات النتروجين والكبريت في طول النبات (سم ) .

\begin{tabular}{|c|c|c|c|c|c|c|c|c|c|}
\hline \multirow[t]{2}{*}{ المتوسط } & \multicolumn{4}{|c|}{ التلقيح } & \multicolumn{4}{|c|}{ بدون تلقيح } & \multirow{2}{*}{ النيتروجين } \\
\hline & المتوسط & $\mathbf{S}_{2}$ & $S_{1}$ & $S_{0}$ & المتوسط & $S_{150}$ & $S_{100}$ & $S_{0}$ & \\
\hline $\begin{array}{c}87.0 \\
\text { b }\end{array}$ & $\begin{array}{c}93.16 \\
\text { cd }\end{array}$ & $\begin{array}{r}102.0 \\
\text { bcdefg }\end{array}$ & $\begin{array}{c}95.0 \\
\text { cdefgh }\end{array}$ & $\begin{array}{c}82.5 \\
\text { hi }\end{array}$ & $\begin{array}{c}80.83 \\
\text { d }\end{array}$ & $\begin{array}{l}100.0 \\
\text { cdefg }\end{array}$ & $\begin{array}{c}75.0 \\
\text { hi }\end{array}$ & $\begin{array}{c}67.5 \\
i\end{array}$ & $\mathbf{N}^{0}$ \\
\hline $\begin{array}{c}95.25 \\
\text { b } \\
\end{array}$ & $\begin{array}{c}98.33 \\
\text { cd } \\
\end{array}$ & $\begin{array}{c}105.0 \\
\text { bcdefg }\end{array}$ & $\begin{array}{l}100.0 \\
\text { cdefg }\end{array}$ & $\begin{array}{c}90.0 \\
\text { efghi }\end{array}$ & $\begin{array}{c}92.16 \\
\text { cd }\end{array}$ & $\begin{array}{c}101.5 \\
\text { bcdefg }\end{array}$ & $\begin{array}{c}90.0 \\
\text { efghi }\end{array}$ & $\begin{array}{l}85.0 \\
\text { fghi }\end{array}$ & $N^{40}$ \\
\hline $\begin{array}{c}108.58 \\
a \\
114.58 \\
a \\
\end{array}$ & $\begin{array}{c}121.66 \\
\text { ab } \\
130.5 \\
\text { a }\end{array}$ & $\begin{array}{c}152.5 \\
\mathrm{a} \\
157.5 \\
\mathrm{a}\end{array}$ & $\begin{array}{c}115.0 \\
\text { bcd } \\
125.0 \\
\text { b } \\
\end{array}$ & $\begin{array}{c}97.5 \\
\text { cdefgh } \\
109.0 \\
\text { bcdef }\end{array}$ & $\begin{array}{c}95.5 \\
\text { cd } \\
98.66 \\
\text { cd } \\
\end{array}$ & $\begin{array}{c}105.0 \\
\text { bcdefg } \\
10.5 \\
\text { bcdef }\end{array}$ & $\begin{array}{c}94.0 \\
\text { cdefgh } \\
96.0 \\
\text { cdefgh }\end{array}$ & $\begin{array}{r}87.5 \\
\text { fghi } \\
92.5 \\
\text { defgh }\end{array}$ & $\begin{array}{l}\mathrm{N}^{80} \\
\mathrm{~N}^{120}\end{array}$ \\
\hline $\begin{array}{c}107.91 \\
\mathbf{a}\end{array}$ & $\begin{array}{c}108.66 \\
\text { bc }\end{array}$ & $\begin{array}{r}105.0 \\
\text { bcdefg }\end{array}$ & $\begin{array}{c}117.5 \\
\text { bc }\end{array}$ & $\begin{array}{c}103.5 \\
\text { bcdefg }\end{array}$ & $\begin{array}{c}107.16 \\
\text { bc }\end{array}$ & $\begin{array}{l}112.5 \\
\text { bcde }\end{array}$ & $\begin{array}{c}115.0 \\
\text { bed }\end{array}$ & $\begin{array}{c}94.0 \\
\text { cdefgh }\end{array}$ & $N^{160}$ \\
\hline & $\begin{array}{c}110.46 \\
\mathrm{a}\end{array}$ & $\begin{array}{c}124.40 \\
\mathrm{a}\end{array}$ & $\begin{array}{c}110.5 \\
\text { ab }\end{array}$ & $\begin{array}{l}96.5 \\
\text { bed }\end{array}$ & $\begin{array}{c}94.86 \\
\text { b } \\
\end{array}$ & $\begin{array}{c}105.3 \\
\text { bc }\end{array}$ & $\begin{array}{c}94.0 \\
\text { cd }\end{array}$ & $\begin{array}{c}85.3 \\
\text { d }\end{array}$ & المتوسط \\
\hline
\end{tabular}

تقارن قيم كل مجموعة من المتوسطات مع بعضها . القيم في المجموعة الواحدة ذات الحروف المتثابه لاتختلف معنويا بينها حسب اختبار دنكن متعدد الحدود بمستوى احتمالد

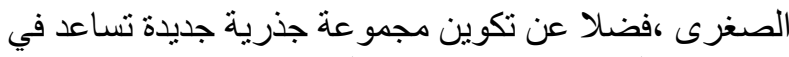
رفع كفاءة النباتات في امتصاص المغن المغذيات.

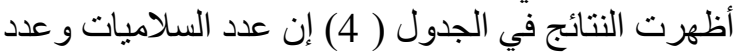

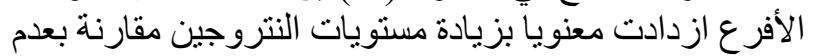

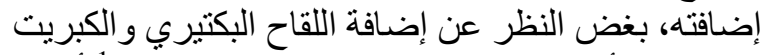

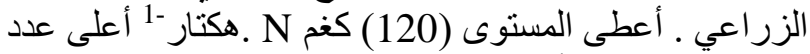

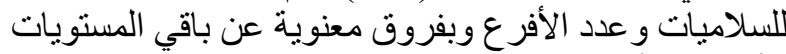

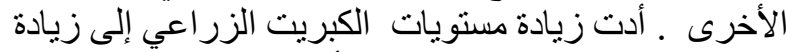

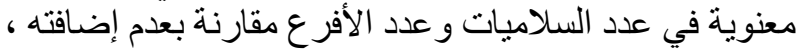

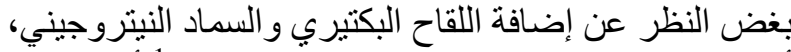

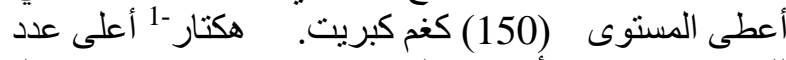
للسلاميات و عدد الأفرع إذ بلغت (

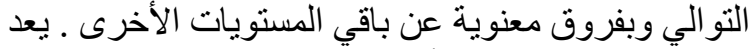

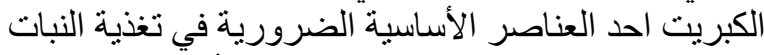
فهو يدخل في تركيب بعض الفيتامينات والأحماض الإني الامينية

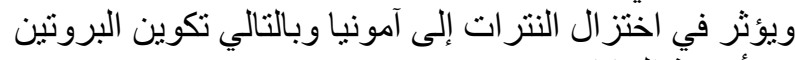

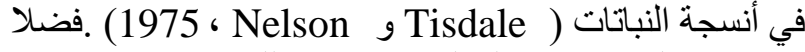

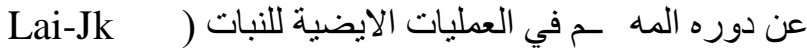

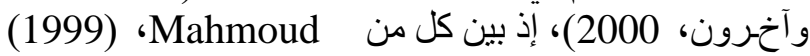

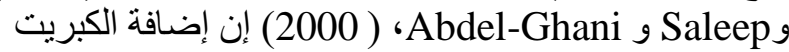
تزيد من النمو الخضري لعدد من المحاصيل. اثر التداخل بين إنين

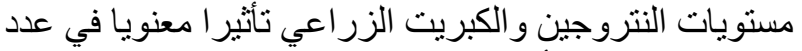
السلاميات و عدد الأفرع، بغض النظير النظر عن إضافة اللقاح

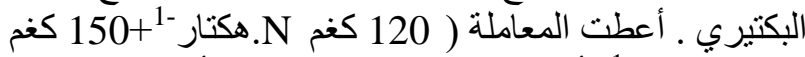

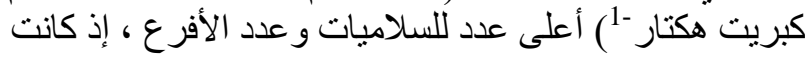

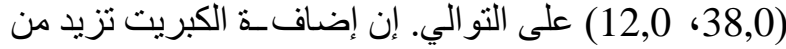

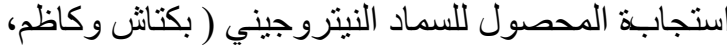

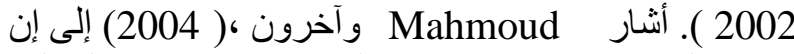

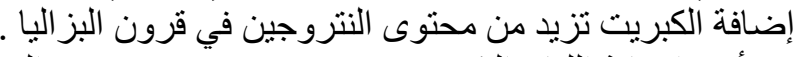

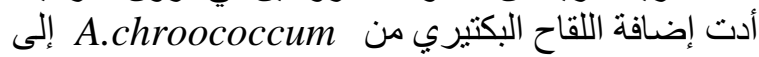

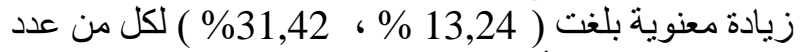
السلاميات و عدد الأفرع على التو الي مقارنة بعدم إضافتها،

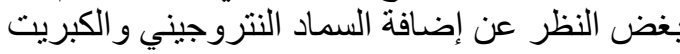
الزر اعي. إذ إن للازوتوباكتر القدرة على إنتاد النتاج مو اد منشطة

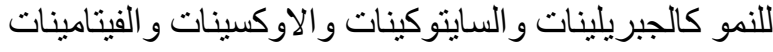

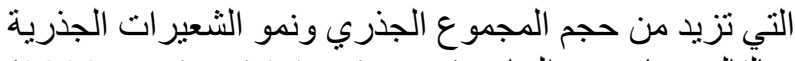

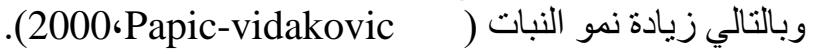

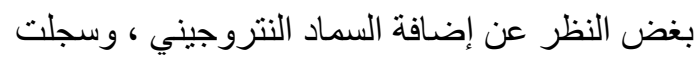

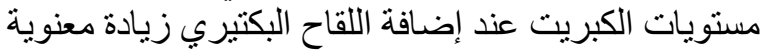

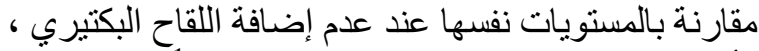

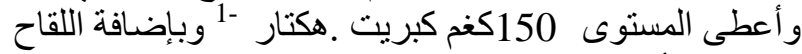

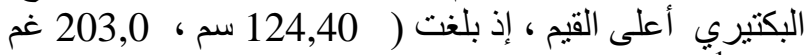

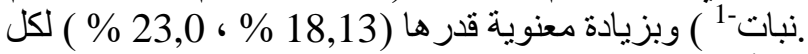

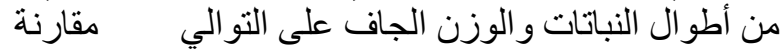

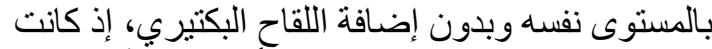

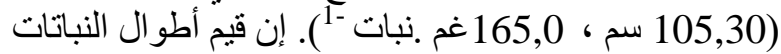

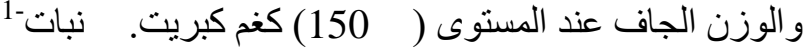
وباضافة اللقاح البكتيري لا تختلف معنويا لافيا عن قيمها عند

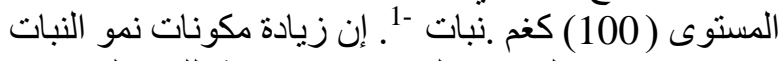

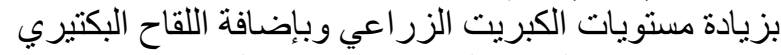

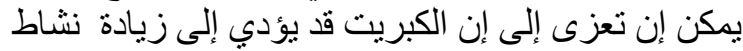

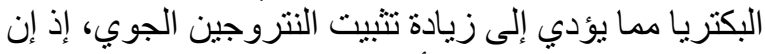

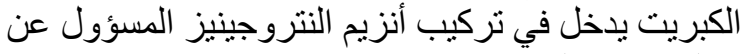

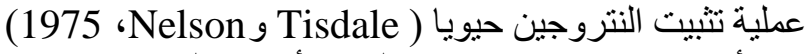
كما أثنار Aleem، (1975) إلى إن أكسدة الكبريت حيويا.

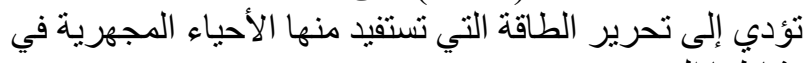

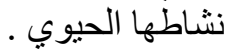

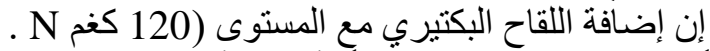

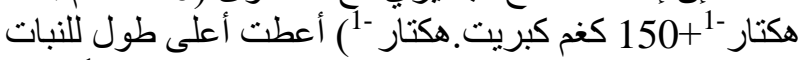

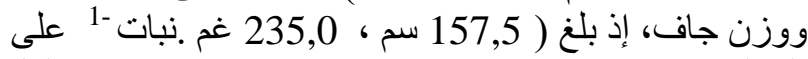

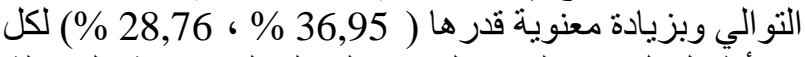

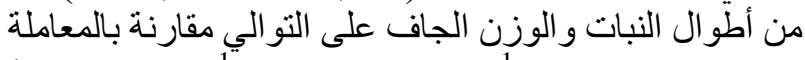

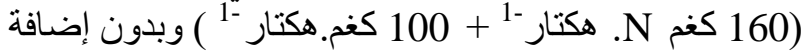

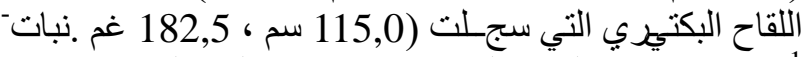

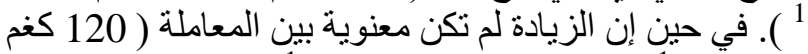

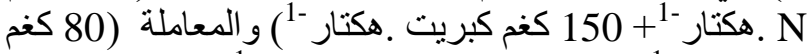

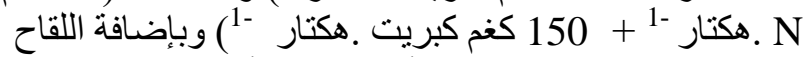

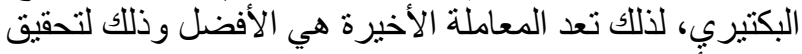

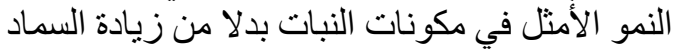

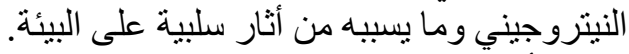

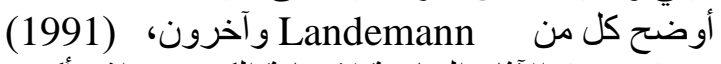

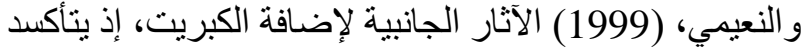

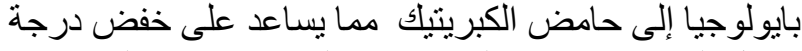

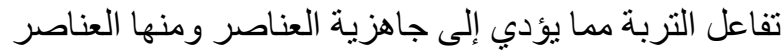




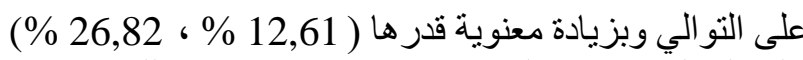

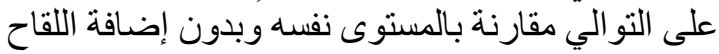

أعطى المستوى ( 160) كغم N هكتار-1 وبدون إضافة اللقاح البكتيري أعلى عدد اللسلاميات و عدد الأفرع إذ بلغت

\begin{tabular}{|c|c|c|c|c|c|c|c|c|c|}
\hline \multirow[b]{2}{*}{ 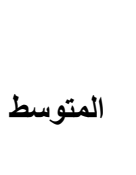 } & \multicolumn{9}{|c|}{ جلول (3): تأثير التلقيح البكتيري ومستويات النتروجين والكبريت في الوزن الجاف (غم .نبات -1 ). } \\
\hline & المعدل & $\mathbf{S 1}_{\mathbf{5 0}}$ & $\mathbf{S}_{\mathbf{1 0 0}}$ & $\mathbf{S}_{\mathbf{0}}$ & المتوسط & $\mathbf{S 1}_{\mathbf{5 0}}$ & $\mathbf{S}_{100}$ & $\mathbf{S}_{\mathbf{0}}$ & النيتروجين \\
\hline $\begin{array}{c}138.33 \\
\text { d }\end{array}$ & $\begin{array}{c}145.0 \\
\text { cd }\end{array}$ & $\begin{array}{l}160.0 \\
\text { fghij }\end{array}$ & $\begin{array}{r}152.5 \\
\text { fghijk }\end{array}$ & $\begin{array}{c}122.5 \\
\text { kl }\end{array}$ & $\begin{array}{c}131.67 \\
\text { d }\end{array}$ & $\begin{array}{c}150.0 \\
\text { fghijk }\end{array}$ & $\begin{array}{c}140.0 \\
\text { hijk }\end{array}$ & $\begin{array}{c}105.0 \\
1\end{array}$ & No \\
\hline $\begin{array}{c}156.66 \\
c\end{array}$ & $\begin{array}{c}169.17 \\
\text { c }\end{array}$ & $\begin{array}{l}200.0 \\
\text { bcde }\end{array}$ & $\begin{array}{l}175.0 \\
\text { defg }\end{array}$ & $\begin{array}{c}132.5 \\
\text { jkl }\end{array}$ & $\begin{array}{c}144.17 \\
\text { Cd }\end{array}$ & $\begin{array}{c}167.5 \\
\text { fghi }\end{array}$ & $\begin{array}{l}142.5 \\
\text { ghijk }\end{array}$ & $\begin{array}{c}122.5 \\
\text { Kl }\end{array}$ & $\mathbf{N 4 0}$ \\
\hline $\begin{array}{r}174.16 \\
b\end{array}$ & $\begin{array}{r}196.67 \\
b\end{array}$ & $\begin{array}{r}215.0 \\
a b\end{array}$ & $\begin{array}{r}200.0 \\
\text { bcde }\end{array}$ & $\begin{array}{r}175.0 \\
\text { defg }\end{array}$ & $\begin{array}{r}151.67 \\
\text { Cd }\end{array}$ & $\begin{array}{r}170.0 \\
\text { efgh }\end{array}$ & $\begin{array}{r}150.0 \\
\text { fghijk }\end{array}$ & $\begin{array}{r}135.0 \\
\text { ijkl }\end{array}$ & N80 \\
\hline $\begin{array}{r}190.41 \\
a\end{array}$ & $\begin{array}{r}226.67 \\
a \\
\end{array}$ & $\begin{array}{r}235.0 \\
a\end{array}$ & $\begin{array}{r}220.0 \\
\text { ab }\end{array}$ & $\begin{array}{r}225.0 \\
a b\end{array}$ & $\begin{array}{r}154.17 \\
\text { Cd }\end{array}$ & $\begin{array}{l}162.5 \\
\text { fghij }\end{array}$ & $\begin{array}{r}160.0 \\
\text { fghij }\end{array}$ & $\begin{array}{r}140.0 \\
\text { hijk }\end{array}$ & N120 \\
\hline $\begin{array}{c}187.91 \\
\text { ab }\end{array}$ & $\begin{array}{c}206.67 \\
\text { ab }\end{array}$ & $\begin{array}{l}205.0 \\
\text { abcd }\end{array}$ & $\begin{array}{c}210.0 \\
\text { abc }\end{array}$ & $\begin{array}{l}205.0 \\
\text { abcd }\end{array}$ & $\begin{array}{c}169.17 \\
\mathrm{C}\end{array}$ & $\begin{array}{c}175.0 \\
\text { defg }\end{array}$ & $\begin{array}{l}182.5 \\
\text { cdef }\end{array}$ & $\begin{array}{l}150.0 \\
\text { fghijk }\end{array}$ & N160 \\
\hline & $\begin{array}{c}188.83 \\
\text { a }\end{array}$ & $\begin{array}{c}203.0 \\
\text { a }\end{array}$ & $\begin{array}{c}191.5 \\
\text { ab }\end{array}$ & $\begin{array}{c}172.0 \\
\text { be }\end{array}$ & $\begin{array}{c}150.16 \\
\text { b }\end{array}$ & $\begin{array}{c}165.0 \\
\mathrm{c}\end{array}$ & $\begin{array}{c}155.0 \\
\text { c }\end{array}$ & $\begin{array}{c}130.5 \\
\text { d }\end{array}$ & المتوسط \\
\hline
\end{tabular}

البكتبري. إن عدد السلاميات و عدد الأفرع عند المستوى

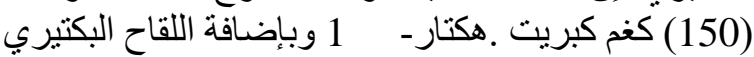

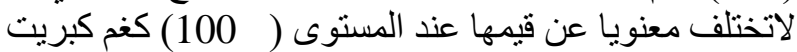

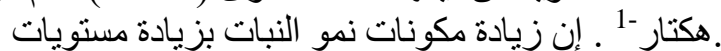

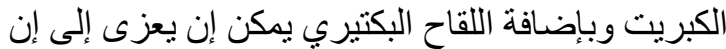

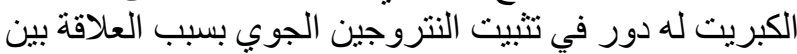

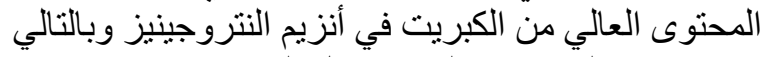

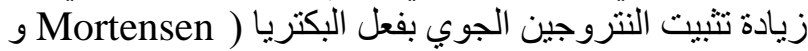
. (1979 ، Thorneley أعطت إضافة اللقاح البكتيري مع المستوى ( 120 كغنم

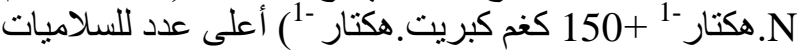

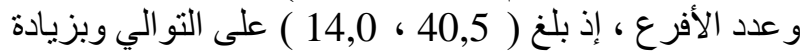

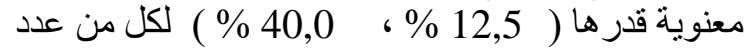
السلاميات و عدد الأفرع على التو الي مقارنة بالمعاملة ( 160

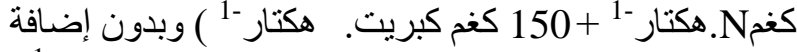

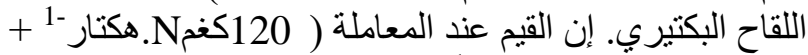

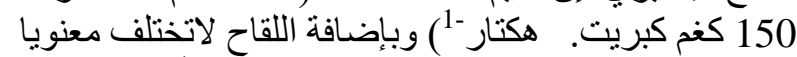

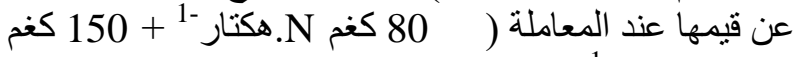
كبريت. هكتار -1 ) مندان

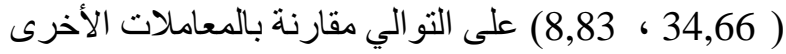

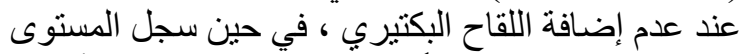

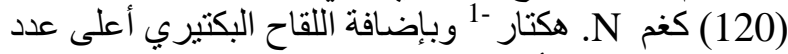
للسلاميات و عدد الأفرع ، إذ بلغت (

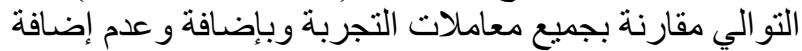

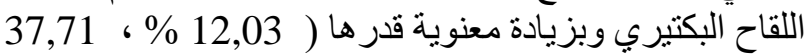

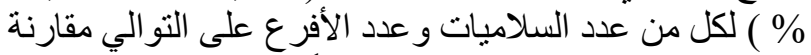

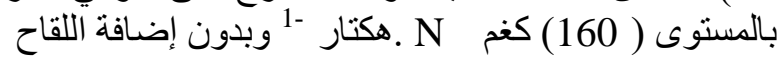

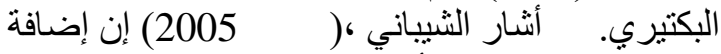
A.chroococcum

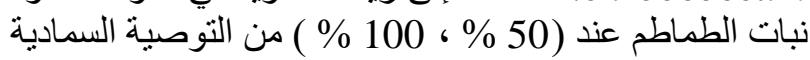

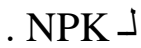
أدت زيادة مستويات الكبريت الزراعي إلى زيادي فيادة غير

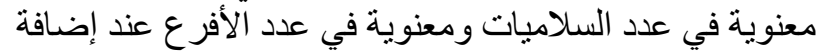

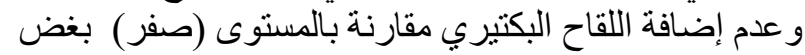

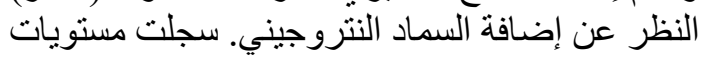

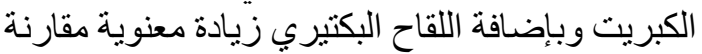

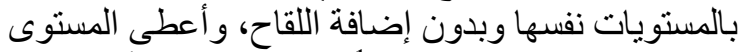

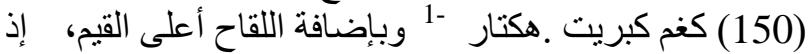
بلغت (36,60، 10,40) لكل من عدد السلاميات و عدد الأفرع الفراح 
جدول (4): تأثير التلقيح البكتيري ومستويات النتروجين والكبريت في عدد السلاميات وعدد الأفرع .

\begin{tabular}{|c|c|c|c|c|c|c|c|c|c|}
\hline \multicolumn{10}{|c|}{ عدد السلاميات } \\
\hline \multirow[t]{2}{*}{ المتوسط } & \multicolumn{4}{|c|}{ التلقيح } & \multicolumn{4}{|c|}{ بدون تلقيح } & \multirow{2}{*}{ النيتروجين } \\
\hline & المتوسط & $S_{150}$ & $S_{100}$ & $\mathbf{S}_{0}$ & المتوسط & $S_{150}$ & $S_{100}$ & $\mathbf{S}_{0}$ & \\
\hline 27.33 & 30.33 & 32.5 & 30.0 & 28.5 & 24.33 & 26.5 & 24.5 & 22.0 & $\mathbf{N}_{0}$ \\
\hline d & de & defghij & ghijk & $\mathbf{i j k l}$ & $\mathbf{F}$ & klm & Im & M & \\
\hline 31.0 & $\begin{array}{l}32.50 \\
\text { bed }\end{array}$ & $\begin{array}{c}\mathbf{3 4 . 0} \\
\text { cdefoh }\end{array}$ & $\begin{array}{c}32.5 \\
\text { defohii }\end{array}$ & $\begin{array}{c}\mathbf{3 1 . 0} \\
\text { fohiik }\end{array}$ & 29.50 & $\begin{array}{c}31.5 \\
\text { efohiik }\end{array}$ & $\begin{array}{l}29.0 \\
\text { hiikl }\end{array}$ & $\begin{array}{l}28.0 \\
\text { Jkl }\end{array}$ & $\mathbf{N}_{40}$ \\
\hline $\begin{array}{c}33.0 \\
\text { c }\end{array}$ & $\begin{array}{c}34.66 \\
\text { b }\end{array}$ & $\begin{array}{c}36.5 \\
\text { abcde }\end{array}$ & $\begin{array}{c}35.0 \\
\text { bcdefg }\end{array}$ & $\begin{array}{c}32.5 \\
\text { defghij }\end{array}$ & $\begin{array}{c}31.33 \\
\text { Cde }\end{array}$ & $\begin{array}{c}\text { 33.0 } \\
\text { defghij }\end{array}$ & $\begin{array}{c}\text { 31.0 } \\
\text { fghijk }\end{array}$ & $\begin{array}{c}\text { 30.0 } \\
\text { ghijk }\end{array}$ & $\mathbf{N}_{80}$ \\
\hline $\begin{array}{c}36.33 \\
\mathbf{a}\end{array}$ & $\begin{array}{c}38.83 \\
\text { a }\end{array}$ & $\begin{array}{c}40.5 \\
\mathrm{a}\end{array}$ & $\begin{array}{l}38.5 \\
\text { abc }\end{array}$ & $\begin{array}{c}37.5 \\
\text { abcd }\end{array}$ & $\begin{array}{c}33.83 \\
\text { bc }\end{array}$ & $\begin{array}{c}35.5 \\
\text { abcdef }\end{array}$ & $\begin{array}{c}34.0 \\
\text { cdefgh }\end{array}$ & $\begin{array}{c}\text { 32.0 } \\
\text { Efghij }\end{array}$ & $N_{120}$ \\
\hline $\begin{array}{c}36.16 \\
\mathrm{a}\end{array}$ & $\begin{array}{c}37.60 \\
\mathrm{a}\end{array}$ & $\begin{array}{l}39.5 \\
\text { ab }\end{array}$ & $\begin{array}{c}37.5 \\
\text { abcd }\end{array}$ & $\begin{array}{c}36.0 \\
\text { abcdef }\end{array}$ & $\begin{array}{c}34.66 \\
\text { b }\end{array}$ & $\begin{array}{c}36.0 \\
\text { abcdef }\end{array}$ & $\begin{array}{c}34.5 \\
\text { bcdefg }\end{array}$ & $\begin{array}{c}33.5 \\
\text { Cdefghi }\end{array}$ & $N_{160}$ \\
\hline & $\begin{array}{c}34.80 \\
\text { a }\end{array}$ & $\begin{array}{c}36.6 \\
\text { a }\end{array}$ & $\begin{array}{c}34.7 \\
\text { ab }\end{array}$ & $\begin{array}{c}33.10 \\
\text { abc }\end{array}$ & $\begin{array}{c}30.73 \\
\text { b }\end{array}$ & $\begin{array}{c}32.50 \\
\text { bed }\end{array}$ & $\begin{array}{c}30.60 \\
\text { cd }\end{array}$ & $\begin{array}{c}29.10 \\
\text { d }\end{array}$ & المتوسط \\
\hline
\end{tabular}

\begin{tabular}{|c|c|c|c|c|c|c|c|c|c|}
\hline \multirow{3}{*}{ المتوسط } & \multirow{2}{*}{\multicolumn{8}{|c|}{ بدون تلقبح }} & \multirow{3}{*}{ النيتروجين } \\
\hline & & & & & & & & & \\
\hline & المتوسط & \multicolumn{2}{|c|}{$S_{150}$} & $S_{0}$ & المتوسط & $S_{150}$ & $S_{100}$ & $\mathbf{S}_{0}$ & \\
\hline $\begin{array}{c}6.0 \\
\text { b }\end{array}$ & $\begin{array}{l}7.0 \\
\text { cde }\end{array}$ & $\begin{array}{c}8.0 \\
\text { cdefg }\end{array}$ & $\begin{array}{c}7.0 \\
\text { defgh }\end{array}$ & $\begin{array}{l}6.0 \\
\text { fgh }\end{array}$ & $\begin{array}{c}5.0 \\
\text { e }\end{array}$ & $\begin{array}{c}6.5 \\
\text { efgh }\end{array}$ & $\begin{array}{l}5.0 \\
\text { gh }\end{array}$ & $\begin{array}{c}3.5 \\
h\end{array}$ & $\mathbf{N}_{0}$ \\
\hline 7.16 & 8.33 & 10.0 & 8.0 & 7.0 & 6.0 & 7.0 & 6.5 & 4.5 & $\mathbf{N}_{40}$ \\
\hline cd & c & bcde & cdefg & defgh & de & defgh & efgh & gh & \\
\hline $\begin{array}{c}8.66 \\
\text { b }\end{array}$ & $\begin{array}{c}10.66 \\
\text { ab }\end{array}$ & $\begin{array}{c}12.0 \\
\text { ab }\end{array}$ & $\begin{array}{l}11.0 \\
\text { abc }\end{array}$ & $\begin{array}{c}9.0 \\
\text { bcdef }\end{array}$ & $\begin{array}{l}6.66 \\
\text { cde }\end{array}$ & $\begin{array}{c}7.5 \\
\text { cdefg }\end{array}$ & $\begin{array}{c}6.5 \\
\text { efgh }\end{array}$ & $\begin{array}{l}6.0 \\
\text { fgh }\end{array}$ & $\mathbf{N}_{80}$ \\
\hline $\begin{array}{c}10.33 \\
\mathrm{a}\end{array}$ & $\begin{array}{c}12.16 \\
\text { a }\end{array}$ & $\begin{array}{c}14.0 \\
\text { a }\end{array}$ & $\begin{array}{c}12.0 \\
\text { ab }\end{array}$ & $\begin{array}{r}10.5 \\
\text { abcd }\end{array}$ & $\begin{array}{c}8.5 \\
c\end{array}$ & $\begin{array}{l}10.0 \\
\text { bcde }\end{array}$ & $\begin{array}{c}8.0 \\
\text { cdefg }\end{array}$ & $\begin{array}{c}7.5 \\
\text { cdefgh }\end{array}$ & $N_{120}$ \\
\hline $\begin{array}{c}8.33 \\
\text { bc }\end{array}$ & $\begin{array}{c}7.83 \\
\text { cd }\end{array}$ & $\begin{array}{c}\mathbf{8} \\
\text { cdefg }\end{array}$ & $\begin{array}{c}8.0 \\
\text { cdefg }\end{array}$ & $\begin{array}{c}7.5 \\
\text { cdefg }\end{array}$ & $\begin{array}{c}8.83 \\
\text { bc }\end{array}$ & $\begin{array}{l}10.0 \\
\text { bcde }\end{array}$ & $\begin{array}{c}9.5 \\
\text { bcdef }\end{array}$ & $\begin{array}{c}7.0 \\
\text { defgh }\end{array}$ & $\mathrm{N}_{160}$ \\
\hline & $\begin{array}{c}9.20 \\
\mathrm{a}\end{array}$ & $\begin{array}{c}10.40 \\
\text { a }\end{array}$ & $\begin{array}{c}9.20 \\
\text { ab }\end{array}$ & $\begin{array}{c}8.0 \\
\text { b }\end{array}$ & $\begin{array}{c}\text { 7.0 } \\
\text { b }\end{array}$ & $\begin{array}{c}8.20 \\
\text { b }\end{array}$ & $\begin{array}{l}7.10 \\
\text { bc }\end{array}$ & $\begin{array}{c}5.7 \\
\text { c }\end{array}$ & المتوسط \\
\hline
\end{tabular}

تقارن قيم كل مجموعة من المتوسطات مع بعضها ـ القيم في المجموعة الواحدة ذات الحروف المتثابه لاتختلف معنويا بينها حسب اختبار دنكن متعدد الحدود بمستوى احتمال0.05 .

Bly الطماطم. هذه النتيجة تتفق مع ما توصل إليه كل من

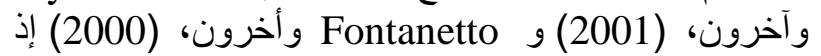

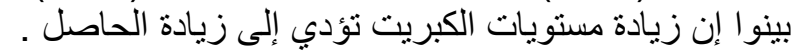

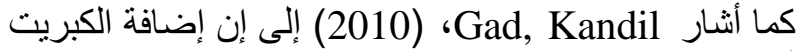

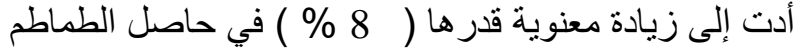

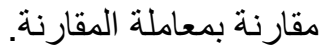

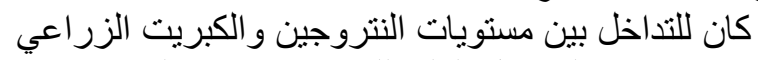

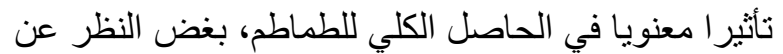

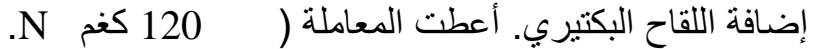

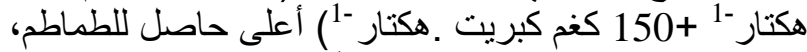

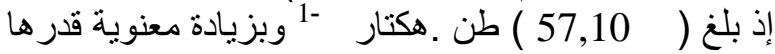

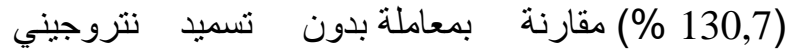

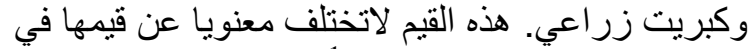

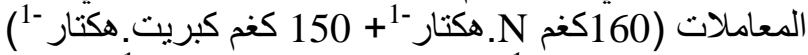

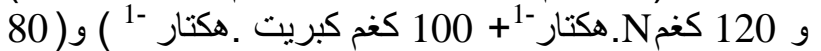

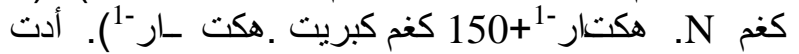
إضافـة اللقـاح البكتيري من ارن
توضح النتائج في الجدول ( 5) إن حاصل الطماطم الكلي

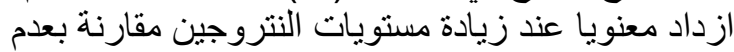

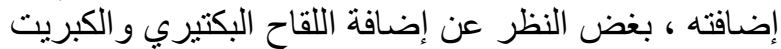

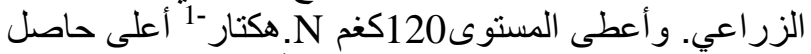

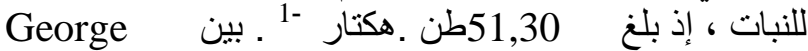

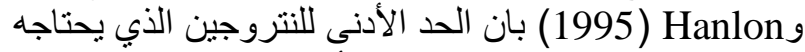

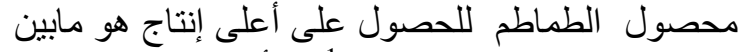

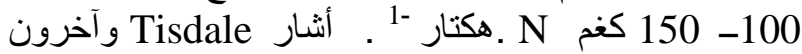
(1997) إلى زيادة حاصل النبات نتيجة إضافة الأسمدة النتروجينية من خلال تحسن الحالة التغذوية للنتروجين. أدت الت التهات

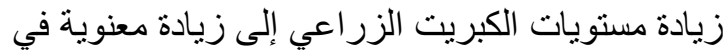

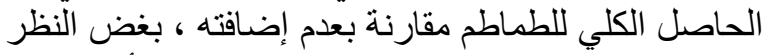

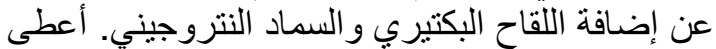

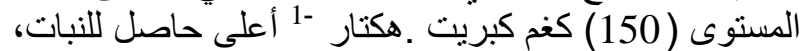

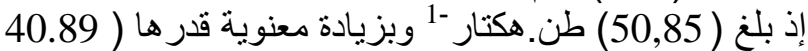

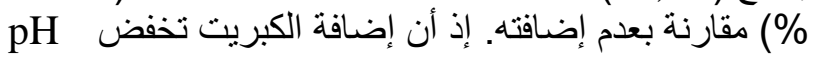

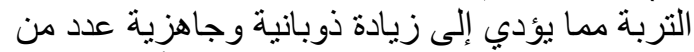

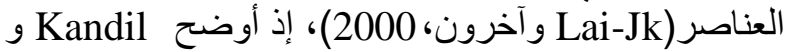

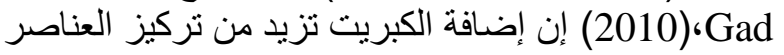
NPK 
جدول (5): تأثير التلقيح ومستويات النتروجين والكبريث في الحاصل الكلي للطماطم (طن ـ هكتار -1 ).

\begin{tabular}{|c|c|c|c|c|c|c|c|c|c|}
\hline \multirow{2}{*}{ المتوسط } & \multicolumn{4}{|c|}{ التلقيح } & \multicolumn{4}{|c|}{ بلون تلقيح } & \multirow{2}{*}{ النيتروجين } \\
\hline & المتوسط & S150 & $S_{100}$ & $\mathbf{S}_{\mathbf{0}}$ & المتوسط & S150 & $S_{100}$ & $\mathbf{S}_{\mathbf{0}}$ & \\
\hline $\begin{array}{c}35.39 \\
\text { c }\end{array}$ & $\begin{array}{c}37.06 \\
\text { cd }\end{array}$ & $\begin{array}{l}42.25 \\
\text { efghi }\end{array}$ & $\begin{array}{l}41.95 \\
\text { efghi }\end{array}$ & $\begin{array}{c}27.0 \\
K\end{array}$ & $\begin{array}{c}33.71 \\
\text { d }\end{array}$ & $\begin{array}{l}40.95 \\
\text { fghi }\end{array}$ & $\begin{array}{c}37.7 \\
\text { ij }\end{array}$ & $\begin{array}{c}22.5 \\
k\end{array}$ & $\mathrm{~N}_{0}$ \\
\hline $\begin{array}{c}40.08 \\
b\end{array}$ & $\begin{array}{l}41.0 \\
\text { bed }\end{array}$ & $\begin{array}{c}47.05 \\
\text { cdefghi }\end{array}$ & $\begin{array}{c}46.35 \\
\text { defghi }\end{array}$ & $\begin{array}{c}29.6 \\
\text { Jk }\end{array}$ & $\begin{array}{c}39.17 \\
\text { bcd }\end{array}$ & $\begin{array}{r}44.85 \\
\text { defghi }\end{array}$ & $\begin{array}{c}44.35 \\
\text { defghi }\end{array}$ & $\begin{array}{c}28.32 \\
k\end{array}$ & $\mathbf{N}_{40}$ \\
\hline $\begin{array}{c}48.52 \\
a\end{array}$ & $\begin{array}{c}51.95 \\
\text { a }\end{array}$ & $\begin{array}{c}59.0 \\
\text { ab }\end{array}$ & $\begin{array}{c}48.8 \\
\text { cdefg }\end{array}$ & $\begin{array}{c}48.05 \\
\text { cdefgh }\end{array}$ & $\begin{array}{c}45.09 \\
\text { abc }\end{array}$ & $\begin{array}{l}50.75 \\
\text { bcdef }\end{array}$ & $\begin{array}{c}47.15 \\
\text { cdefghi }\end{array}$ & $\begin{array}{c}37.37 \\
\text { ij }\end{array}$ & $\mathbf{N}_{80}$ \\
\hline $\begin{array}{c}51.3 \\
\text { a }\end{array}$ & $\begin{array}{c}54.73 \\
\text { a }\end{array}$ & $\begin{array}{c}60.1 \\
\text { ab }\end{array}$ & $\begin{array}{c}56.30 \\
\text { abc }\end{array}$ & $\begin{array}{c}47.90 \\
\text { Cdefgh }\end{array}$ & $\begin{array}{c}47.83 \\
\text { ab }\end{array}$ & $\begin{array}{c}54.1 \\
\text { abcd }\end{array}$ & $\begin{array}{l}50.9 \\
\text { bcde }\end{array}$ & $\begin{array}{l}38.5 \\
\text { Hij }\end{array}$ & $\mathbf{N}_{120}$ \\
\hline $\begin{array}{c}48.35 \\
a\end{array}$ & $\begin{array}{c}45.26 \\
\text { abc }\end{array}$ & $\begin{array}{l}48.95 \\
\text { cdefg }\end{array}$ & $\begin{array}{c}46.8 \\
\text { cdefghi }\end{array}$ & $\begin{array}{c}40.05 \\
\text { Ghi }\end{array}$ & $\begin{array}{c}51.43 \\
\text { a }\end{array}$ & $\begin{array}{c}60.5 \\
a\end{array}$ & $\begin{array}{l}52.15 \\
\text { abcd }\end{array}$ & $\begin{array}{l}41.65 \\
\text { efghi }\end{array}$ & $\mathrm{N}_{160}$ \\
\hline & $\begin{array}{c}46.01 \\
a\end{array}$ & $\begin{array}{c}51.47 \\
\text { a }\end{array}$ & $\begin{array}{c}48.04 \\
a\end{array}$ & $\begin{array}{c}38.52 \\
\text { B }\end{array}$ & $\begin{array}{c}43.43 \\
\text { b }\end{array}$ & $\begin{array}{c}50.23 \\
\text { a }\end{array}$ & $\begin{array}{c}46.45 \\
a\end{array}$ & $\begin{array}{c}33.66 \\
\text { B }\end{array}$ & المتوسط \\
\hline
\end{tabular}




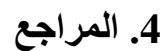

التلال،حسين. ( 2000). زر اعة الطماطم في المناطق

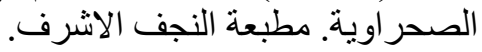

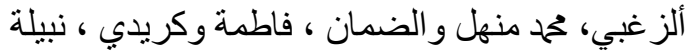

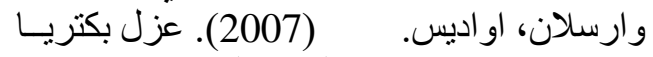

الازوتوباكتر من بعض الترب التوبن السورية واختبار

فعاليتها في تثبيت الازوت باكن الجوب في التربة.

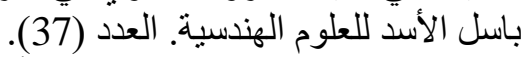

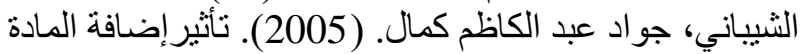

العضوية والمبيد الحيوي و البكتيري A.chroococcum في نمو وحاصل نبات الطيات

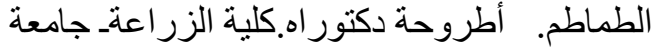

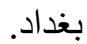

النعيمي، سعد الله نجم عبد الله. ( 1999). الأسمدة وخصوبة

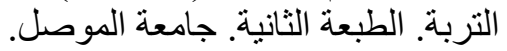

بكتاش، فاضل يونس وكاظم، محمد هذال ( 2002) استجابة

الحنطة لمستويات من السماد النتروجيني و الكبريت.

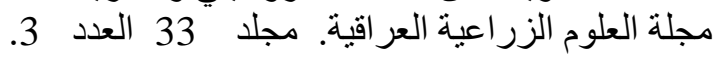
صفحة (135 - 142).

سهيل، فارس حمحد و عبود، تحمد علي وفرحان، لؤي دأي داود. (2010). تأثير التداخل بين بكتريـ

Azotobacter chroococcum و المادة العضوية

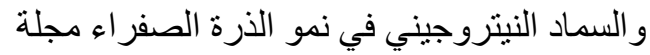

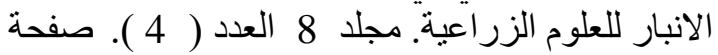
(181-172)

محمود، سعد علي زكي، عبد الوهاب محمد عبد الحافظ، محمد

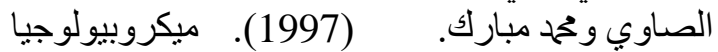

الأر اضي. الطبعة الثانية، القاهرة

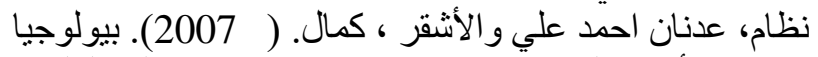
الأحياء الدقيقة ـ منشور ات جامعة ، كمشق ـ ـ كلية العلوم.

\section{REFERENCES}

Aleem M. I. H.(1975). Biochemical reaction mechanisms in sulfur oxidation by synthetic bacteria. Plant Soil 43:578-607.

Alexander M. (1977). Introduction to soil microbiology. $2^{\text {nd }}$ ed. John Wiley and Sons.New York

Beck D. P., Materon L. A., and Afandi F. (1993). Partical Rhizobiumlegume technology. Mannual, No. 9 ICARDA. Aleppo, Syria

Bly H., Woodard H. and Winter D. (2001). Corn response to sulfur application. pub. South Dakota University. pp. 1-4.
A.chroococcum

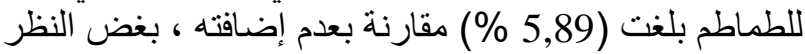

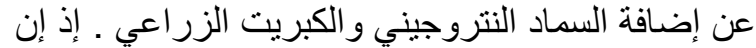

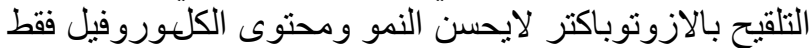

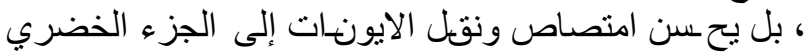

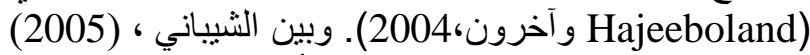
إن إضافة بكتريا A.chroococcum أدت إلى زيادة معنوية الثية

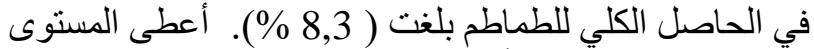

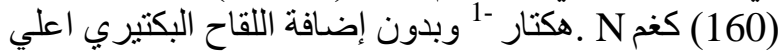

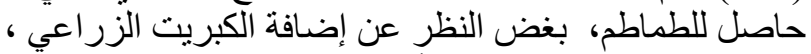

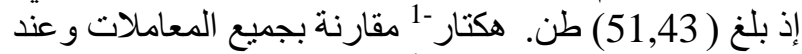

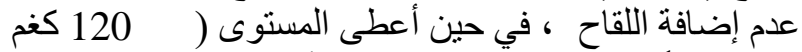

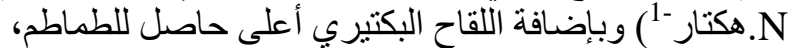

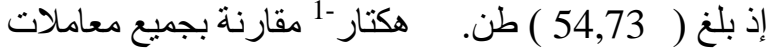

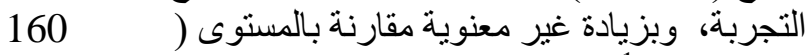

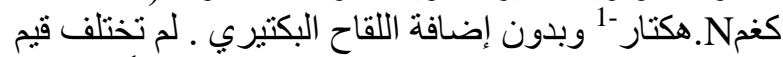

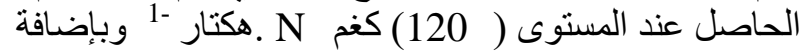
اللقاح البكتيري معنويا عن قيمها عند المستوى (

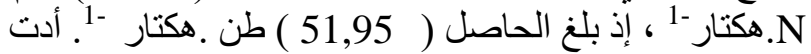

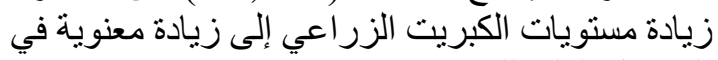

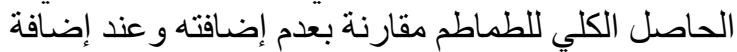

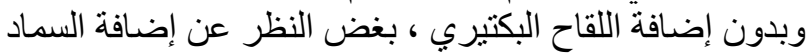

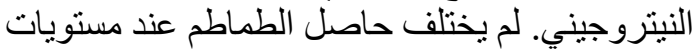

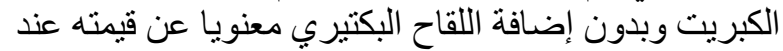
المستويات نفسها وبإضافة اللقاح البكتيري. أعطت المبري المعاملة

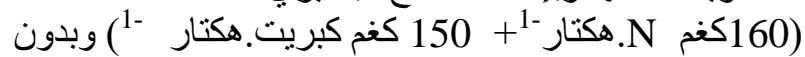
إضافة اللقاح البكتيري أعلى حاصل للطماطم، إذ بلغ ( 60,5)

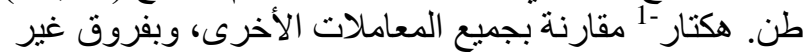

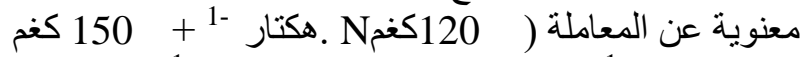

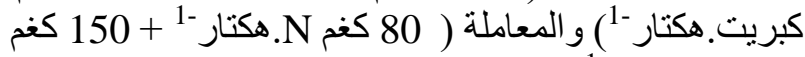

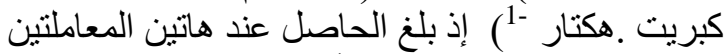

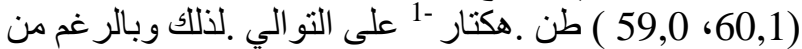

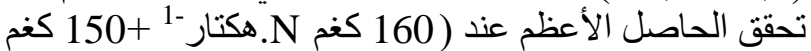

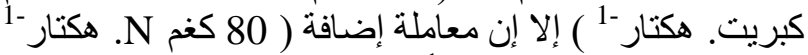
150 +

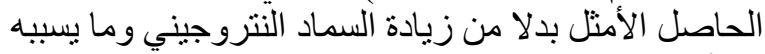

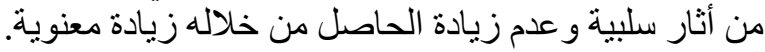

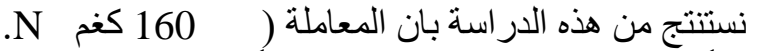

هكتار -1 + 150 كغم كبريت. هكتار

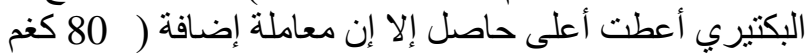

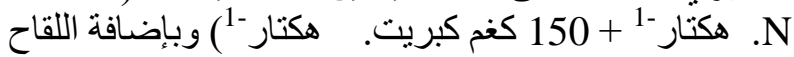
البكتيري تعد المعاملة المفضلة لان زئن إديادة السماد النيتروجيني

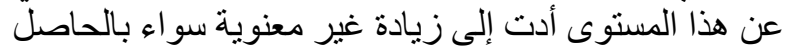

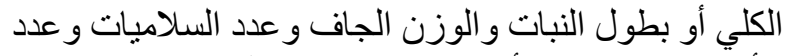

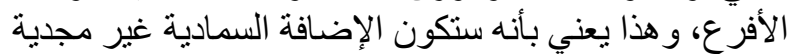

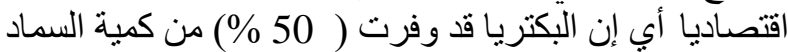

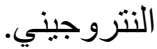


Fontanetto H., Keller O., Inwinkelried R., Citroni

N. and Garca F. ( 2000). Phosphorus and sulfur fertilization of corn in the northern pampas. Better Crops Inter.14 (1):1-4.

George J. H. and Hanlon E. A. (1995). Comercial vegetable crop nutrient require-ments in Florida. Gainesville. Univ. of Florida. SP 177. Florida Coop.Ext. Serv .

Govedarica M., Milic V. and Grozdenovic D. J (1993). Efficiency of the association between Azotobacter chroococcum and some tomoto varieties. Zemljiste-i-biljka (Yugoslavia) V.42 (2), P. 113-120.

Govedarica M., Tasic M., Milosvic N. and Jarak M. (1995 ). Nitrogen- fixing organisms applied in wheat production. Sovremena-poljoprivreda (Yugoslavia). 49: 127-131.

Hajeeboland R., Asgharzadeh N. and Mhrfar Z. (2004).Ecological study of Azotobacter in two pasture lands of the north - west Iran and its inoculation effect on growth and mineral nutrition of wheat plant.Journal of Science and Technology of Agriculture and natural Resources. V. 8 P : 75- 90.

Janzen H. H and Betteny J. R. (1984).Sulphur nutrition of rafe seed influence of fertilization nitrogen and sulphur rates. Soil Sci.Soc. Am.J.48.100-107.

Kandil H. and Gad N. (2010). Response of tomato plants to sulphur and organic fertilizer .International Journal of Academic Research. V.2 No.3 P: 204- 210.

Lai-JK., Mishra B. and Sarkar Ak. (2000). Effect of sulphur on availability of some plant nutrients. Indian J.Society of Soil Science. 48 (1): 67-71.

Landemann W.C., Aburto J.J., Haffiner W and Bono A. (1991). Effect of sulfur on sulfur oxidation. Soil Sci. Soc. Am. J. 55:85-90.

Mahmoud Assmaa R., Hafeez Magda M. and Ahmed A. A.(2004). Response of pea plant to the sulphur addition with organic and inorganic nitrogen fertilizer. Egypt J. Appl. inorganic nitrogen fertilizer. Egypt J. Appl. Sci. 19 (2) : 245-261.

Mahmoud F.L. (1999).Effect of sulphur application on plant growth, yield components and chemical constituents of pea cultivates. Egypt. J. Appl. Sci.13(4) :111-118 .

Mashhoor W. A., El-Borollosy M. A., Selim Sh., Nasr Sohair A. and Abdel-Azeem Hoda H.M.. (2002). Production of an $\mathrm{N}_{2}$-fixing inoculant resistant to environmental stress condition for application as N-Bio-Fertilizer in desert soil .Ura b univ. J.Agric. Sci,Ain Shams Univ.Cairo. 10 (2): 567-580

Mortensen L.E. and Thornley R.N.F. (1979). Structure and function of nitrogennase. Ann. Rev. Biochem. 48: 387- 418.

Narula N. (2000). Azotobacter as an organism. Azotobacter in sustainable Agriculture ch (1).ed Neetr N. India.

Papic-Vidakovic T. (2000). An efficiency of Azotobacter soil. Univerzitet u Novom sadu, Novi sad (Yugoslavia). Poljprivredni fakultet.

Sajid M. N., Zahir A., Naveed M., Arshad M . and Shahzad S.M.(2006). Variation in growth and ion uptake of maize due to inoculation with plant growth promoting rhizobacteria under salt stress. Soil and Environ. 25(2):78- 84.

Saleep S.R. and Abdel-Ghani M.M. (2000). Effect of sulphur application and Rhizobium inoculation on growth, nodulation and yield of soybean, Egypt J.Appl.Sci.15 (4):93-101.

Tisdale S.L., and Nelson W.L.(1975). Soil Fertility and Fertilizers. $3^{\text {rd }}$ ed. MacMillan Publishing Co., Inc., New York.

Tisdale S.L.,Nelson.W.L.and Beaton J.D.(1986).Soil fertility and ferilizers. MacMillan publishing company,New York.Collier MacMillan publishing London.

Tisdale S.L., Nelson W.L., Beaton J.D. and Havlin J.L. (1997). Soil fertility and fertilization $5^{r d}$ Ed. prentices. Hall of India Pvt .Ltd. Newdelhi-110001. 